\title{
Anti-acid Corrosion Property of Concrete Improved by Microstructure Optimizing
}

\author{
$L \mathrm{Yu}^{l}, S X \mathrm{Zhang}^{2}$, and $L \mathrm{Chen}^{2}$ \\ ${ }^{1}$ Research institute of highway ministry of transport, No.8 yard, Xi tu cheng Road, Hai-dian district, Beijing, China. \\ ${ }^{2}$ Beijing Xin-Qiao Technology Development Co., LTD, No.8 yard, Xi tu cheng Road, Hai-dian district, Beijing, China
}

\begin{abstract}
To enhance the performance of anti-acid erosion, silica fume, silicon nitride, organic silicone emulsion agent and fly ash ceramsite are all mixed into concrete as admixture. The acid corrosion environment is simulated by laboratory test. Compressive strength of concrete with different curing ages are tested. Compressive strength and pore distribution of concrete dipping in sulphate and in hydrochloride for $90 \mathrm{~d}$ are tested. The result shows that concrete with additional materials has better anti-acid corrode performance than the common one. The compressive strength of concrete with additional materials is higher than the common concrete. The pore distribution curve of the concrete with additional materials can keep steady no matter in sulphate or in hydrochloride. This kind of concrete with high anti-acid corrosion durability has been used in the piles construction of the bridges which is surrounded by acid soil and play an important role in enhancing the durability of the bridge.
\end{abstract}

\section{Introduction}

A bridge called Lao $\mathrm{Hu}$ Shan Chong is located on Mengzi highway in Yunnan province. There was a scrap iron treatment plant before. Now the bridge will be built there. By detection, 12 piles from No.1 to No. 3 piers will be in an environment of ions including $\mathrm{H}^{+}, \mathrm{Cl}^{-}$and $\mathrm{SO}_{4}{ }^{2-}$. So, making a kind of anti-acid erosion concrete material is necessary.

There are several methods to produce anti-acid erosion concrete including raw materials and mix proportion optimized [1]. For example, put some micro or nano materials into concrete to fill macro pores [2][3]. Hydrophobic materials are also often used to improve the permeability performance of concrete [4]. Internal curing materials can be used to decrease the probability of early age cracking in concrete [5]. All of these can enhance the concrete microstructure durability.

Therefore, these kinds of methods are all used to optimize the concrete microstructure. Two series of concrete has been made. One is the control group with no additions and the other is the treatment group with micro materials, hydrophobic materials and internal curing materials in it. And then put the two groups of specimens into acid liquid. After 90 days, test the microstructure, compressive strength, permeated height of $\mathrm{Cl}^{-}$ions to verify the anti-acid performance of concrete. Prepare for the pile construction of Lao Hu Shan Chong Bridge in Mengzi city, Yunnan Province in China.

\section{Raw materials and mix proportion}

\subsection{Raw materials}

The main binding material is P.O 42.5 Portland cement which is produced by Hua Xin cement plant. The fine aggregate is nature sand whose fineness modulus is 2.8 . The coarse aggregate is crushed stone whose diameter is $5-20 \mathrm{~mm}$. Polycarboxylic acid water reducer whose water-reducing rate is $20 \%$ has been used.

Silica fume is necessary. It is used for filling the micro pores in concrete which is produced by Shang Hai Yao Qian Construction Coating and Decorate Co., LTD. The properties of silica fume are listed in table 1 .

Table 1. The properties of silica fume

\begin{tabular}{|l|l|l|}
\hline $\begin{array}{l}\text { Diameter } \\
\mu m\end{array}$ & $\begin{array}{l}\text { Density } \\
\mathrm{kg} / \mathrm{m}^{3}\end{array}$ & $\begin{array}{l}\text { Specific surface area } \\
\mathrm{m}^{2} / \mathrm{kg}\end{array}$ \\
\hline 0.2 & 3200 & 15000 \\
\hline
\end{tabular}

The other silica material is nano silicon nitride which is produced by Qin Huang Dao Yi Nuo New Materials Development Co., LTD. It is used for filling the nano pores in concrete. The properties of silicon nitride are listed in table 2.

Table 2. The properties of silica nitride

\begin{tabular}{|l|l|l|}
\hline $\begin{array}{l}\text { Diameter } \\
\mathrm{nm}\end{array}$ & $\begin{array}{l}\text { Density } \\
\mathrm{kg} / \mathrm{m}^{3}\end{array}$ & $\begin{array}{l}\text { Specific surface area } \\
\mathrm{m}^{2} / \mathrm{kg}\end{array}$ \\
\hline 20 & 90 & 50000 \\
\hline
\end{tabular}


The water-proofing agent of organic silicone emulsion is used in concrete which is produced by Nan Xiong Ding Cheng new material technology Co., LTD. It is used to resistance the permeating of harmful ions. The properties are listed in table 3 .

Table 3. Properties of organic silicone emulsion

\begin{tabular}{|l|l|l|}
\hline Style & PH & Effective Ingredient \\
\hline FS-170 & 7.0 & $>95 \%$ \\
\hline
\end{tabular}

Fly ash ceramsite is used for inner curing for concrete. The properties are listed in table 4.
Table 4. Properties of silica nitride fly ash ceramsite

\begin{tabular}{|c|c|c|}
\hline $\begin{array}{c}\text { Apparent density } \\
\mathrm{kg} / \mathrm{m}^{3}\end{array}$ & $\begin{array}{c}\text { Diameter } \\
\mathrm{mm}\end{array}$ & $\begin{array}{c}\text { Saturated percent } \\
\text { sorption } \%\end{array}$ \\
\hline 1950 & $2-5$ & 42.3 \\
\hline
\end{tabular}

\subsection{Mix proportion}

There are two mix proportions. One is the control group which has no adding materials. It will be shown as symbol $\mathrm{C}$ in the following paragraphs. The other is the treatment group which includes silica fume, silicon nitride, organic silicone emulsion agent and fly ash ceramsite. This group will be named $\mathrm{T}$ in the following paragraphs. Table 5 shows the mix proportions of concretes.

Table 5. Mix proportions of concrete Unit: $\mathrm{kg} / \mathrm{m} 3$

\begin{tabular}{|c|c|c|c|c|c|c|c|c|c|c|}
\hline ID & Cement & Water & Nature sand & $\begin{array}{c}5 \mathrm{~mm}- \\
10 \mathrm{~mm} \\
\text { crushed } \\
\text { stone }\end{array}$ & $\begin{array}{c}10 \mathrm{~mm}- \\
20 \mathrm{~mm} \\
\text { crushed } \\
\text { stone }\end{array}$ & $\begin{array}{c}\text { Silicon } \\
\text { nitride }\end{array}$ & Silica fume & Ceramsite & $\begin{array}{c}\text { Organic } \\
\text { silicone } \\
\text { emulsion } \\
\text { agent }\end{array}$ & $\begin{array}{c}\text { Water } \\
\text { reducer }\end{array}$ \\
\hline $\mathrm{C}$ & 360 & 170 & 817 & 325 & 758 & 0 & 0 & 0 & 0 & 2.88 \\
\hline $\mathrm{T}$ & 360 & 170 & 721 & 308 & 720 & 2 & 20 & 54.5 & 3.82 & 2.05 \\
\hline
\end{tabular}

The slumps of $\mathrm{C}$ and $\mathrm{T}$ are all $180 \mathrm{~mm} \pm 10 \mathrm{~mm}$.

\section{Test methods}

\subsection{Specimens prepare}

For each mix proportion, making 6 groups of concrete and each group has 3 specimens. Four groups are used for testing the $7 \mathrm{~d}, 28 \mathrm{~d}, 56 \mathrm{~d}$ and $90 \mathrm{~d}$ compressive strengths. One group is used for dipping in the acid solution for $90 \mathrm{~d}$ and then testing the compressive strength. One group is used for testing the depth of penetration of $\mathrm{Cl}$ - ion. All of the specimens are $100 \mathrm{~mm}$

\subsection{Acid solution prepare}

Two kinds of solution have been made. One includes hydrochloric acid $(\mathrm{HCl})$ and sodium chloride $(\mathrm{NaCl})$. The other includes sulfuric acid $\left(\mathrm{H}_{2} \mathrm{SO} 4\right)$ and sodium sulfate ( $\mathrm{Na} 2 \mathrm{SO} 4)$. The $\mathrm{PH}$ value of these two solutions is all 2. The percentage of salt is all 3\%. During the digging period, the $\mathrm{PH}$ value of solution should be test every day. If necessary, add additional acid to keep the $\mathrm{PH}$ value of the solution staying at 2 .

\subsection{Microstructure test}

After testing the $90 \mathrm{~d}$ compressive strength, the specimens which had been dipped in the acid solution for $90 \mathrm{~d}$ will be crushed by a machine. The round shaped mortar particles about $10 \mathrm{~g}$ will be selected. After washing these particles with ultrasonic cleaner, put them into the air dry oven and dry under the temperature of $105^{\circ} \mathrm{C} \pm 5^{\circ} \mathrm{C}$ for $24 \mathrm{~h}$. Then put these particles into dryer and cool under nature environment. Test the pore structure by Mercury Injection Apparatus [6].

\subsection{Penetration depth test}

Split off the specimens after 90d dipping in the acid solution. Use phenolphthalein to titrate the split surface. The colour of split surface where has been eroded by $\mathrm{Cl}^{-}$ will become white. Partition it by 10 sections and read the length of white place.

\section{Test results and analysis}

\subsection{Compressive strength analysis}

After curing the specimens for $7 \mathrm{~d}, 28 \mathrm{~d}, 56 \mathrm{~d}$ and $90 \mathrm{~d}$, test the compressive strengths and compare them. Fig. 1 shows the different strength along with different ages.

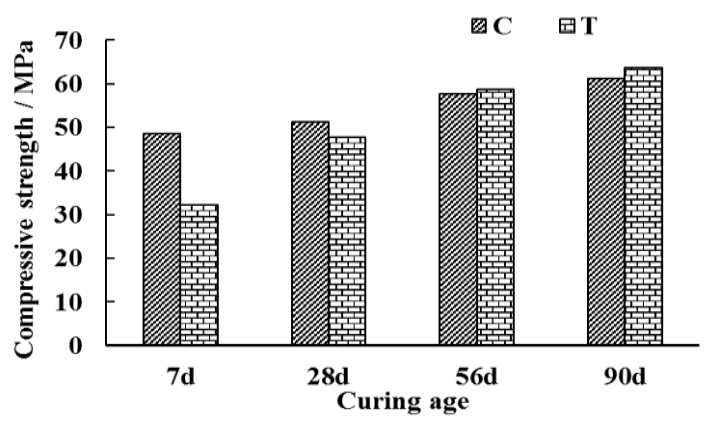

Fig.1. Compressive strength VS curing age 
From Fig. 1, the $7 \mathrm{~d}$ compressive strength of $\mathrm{T}$ concrete is lower than $\mathrm{C}$ concrete. But $28 \mathrm{~d}, 56 \mathrm{~d}$ and $90 \mathrm{~d}$ compressive strengths of $\mathrm{T}$ concrete are all higher than $\mathrm{C}$ concrete. By increasing of curing age, the strength of $\mathrm{T}$ is higher than $\mathrm{C}$. This is because the micro pores have been filled by nano and micro silica materials. In order to analyse the reason, pore structure of $\mathrm{C}$ and $\mathrm{T}$ concretes have been detect by Mercury Injection Apparatus. Fig. 2 shows the pore distribution of concretes.

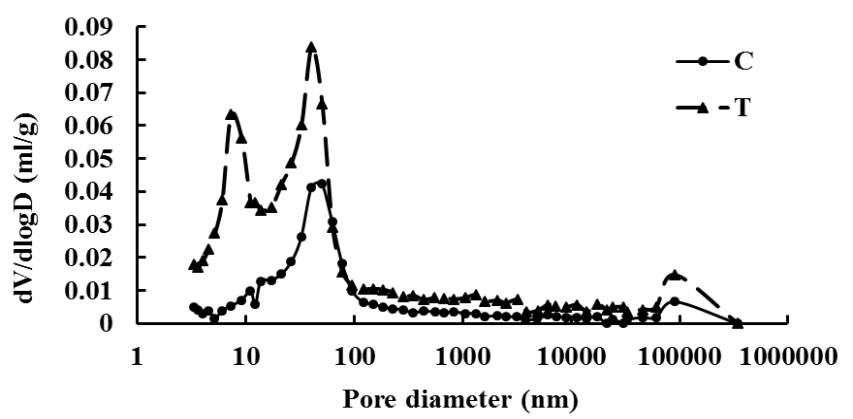

Fig.2. Pore distribution at the curing age of $28 \mathrm{~d}$

From Fig. 2, the amount of the pore whose diameter is under $100 \mathrm{~nm}$ in $\mathrm{T}$ group is more than $\mathrm{C}$ group. According to the theory of $\mathrm{IO} \bullet \mathrm{M}$ Butt, pores under $100 \mathrm{~nm}$ is good to the compressive strength of concrete. So $\mathrm{T}$ is better than $\mathrm{C}$ due to the filling of silica fume, silicon nitride, organic silicone emulsion agent and fly ash ceramsite.

\subsection{Anti-acid performance analysis}

Acid is bad for concrete including appearing, compressive strength, permeability. Partial reasons are that acid can destroy the pore structure in concrete.

\subsubsection{Appearance of concrete}

Fig. 3 and Fig. 4 shows the concrete appearance after 90d digging in acid solution.

In the solution of sulfuric acid and sodium sulfate, the concrete surfaces are denudated. In the solution of hydrochloric acid and sodium chloride, the concrete surfaces are as same as before.
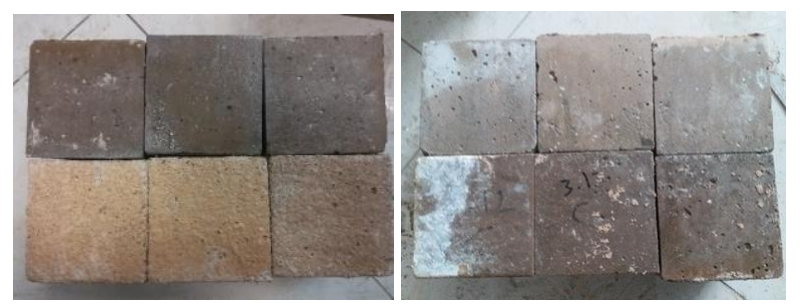

Fig.3. Sulfuric acid

Fig.4. Hydrochloric acid

Scrape the exfoliation on the concretes which have been dipped in sulfuric acid and then dry and weigh it. The exfoliation from $\mathrm{C}$ is about $1.9 \%$ while the one from $\mathrm{T}$ is just $0.6 \%$. So $\mathrm{T}$ group is more corrosion resistance.

\subsubsection{Compressive strength}

To compare two different kinds of concrete, the rate of compressive strength decreasing has been calculated by formula 1 .

$$
\Delta C S=\frac{C S-C S_{0}}{C S_{0}} \times 100 \%
$$

$\triangle \mathrm{CS}$ - The rate of compressive strength decreasing. CS-Compressive strength of concrete after 90d dipping in the acid solution.

$\mathrm{CS}_{0}$ - Compressive strength of concrete with the same curing age but without acid solution corroded.

Fig. 5 is about the concretes which are dipped in sulfuric acid solution for ages of $28 \mathrm{~d}, 56 \mathrm{~d}$ and $90 \mathrm{~d}$. C$\mathrm{SO} 4$ is the control group which has no addition materials in it. T-SO4 is the treatment group which has silica fume, silicon nitride, organic silicone emulsion agent and fly ash ceramsite in it.

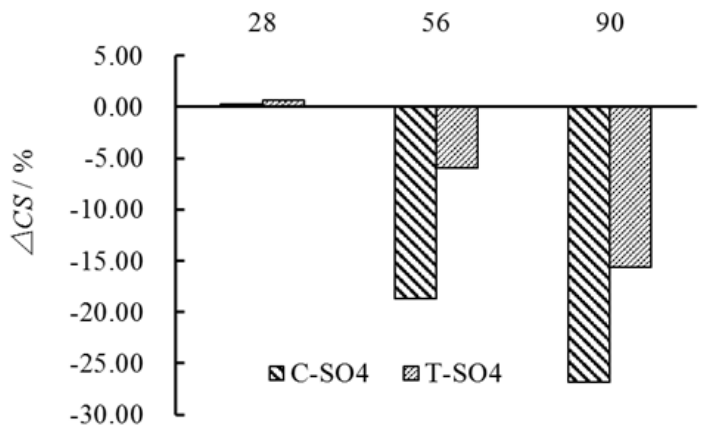

Fig.5. Compressive strength decreasing rate of concrete in sulfuric acid and sodium sulfate solution

From Fig. 5, in the same solution, at the age of $90 \mathrm{~d}$, the decreasing of compressive strength of T-SO4 group is less than $\mathrm{C}-\mathrm{SO} 4$ group. It means $\mathrm{T}-\mathrm{SO} 4$ group has better anti-acid corrode performance. The data at the age of $28 \mathrm{~d}$ is unusual. The compressive strength is higher than curing group. This is because the sodium sulfate which can react with the ettringite in the surface layer of concrete. Due to this reason, the pores in the concrete have been filled and the compressive strength is higher than before. But by the time passing, the delay ettringite expands and the strength of concrete decreases.

Fig. 6 is about the concretes which are dipped in hydrochloric acid solution for ages of $28 \mathrm{~d}, 56 \mathrm{~d}$ and $90 \mathrm{~d}$. $\mathrm{C}-\mathrm{Cl}$ is the control group which has no addition materials in it. $\mathrm{T}-\mathrm{Cl}$ is the treatment group which has silica fume, silicon nitride, organic silicone emulsion agent and fly ash ceramsite in it. 


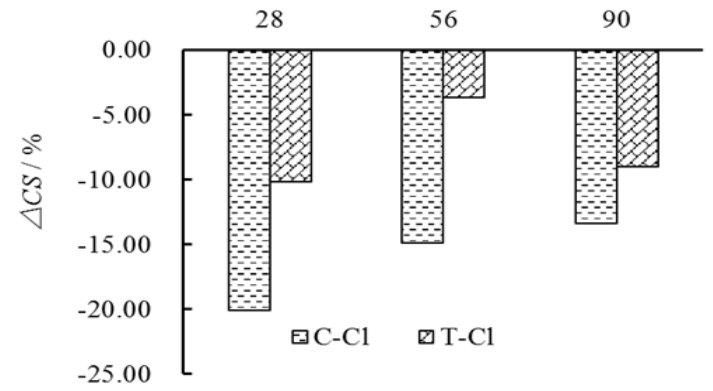

Fig.6. Compressive strength decreasing rate of concrete in hydrochloric acid and sodium chloride solution

From Fig. 6, $\mathrm{C}-\mathrm{Cl}$ group is worse than $\mathrm{T}-\mathrm{Cl}$. That means the concrete which has additional materials has better anti-acid and chlorine salt corrode performance.

\subsubsection{Pore distribution}

To compare the vary of pore distribution of concrete, Fig. 7 and Fig. 8 are plotted. In Fig. 7, there are two lines. C is the concrete which hasn't been dipped in acid solution but only curing in water. C-SO4 is the concrete which has been dipped in sulfuric acid solution. In Fig. 8, there are also two lines. $\mathrm{T}$ is the concrete which hasn't been dipped in acid solution but only curing in water. T-SO4 is the concrete which has been dipped in sulfuric acid solution.

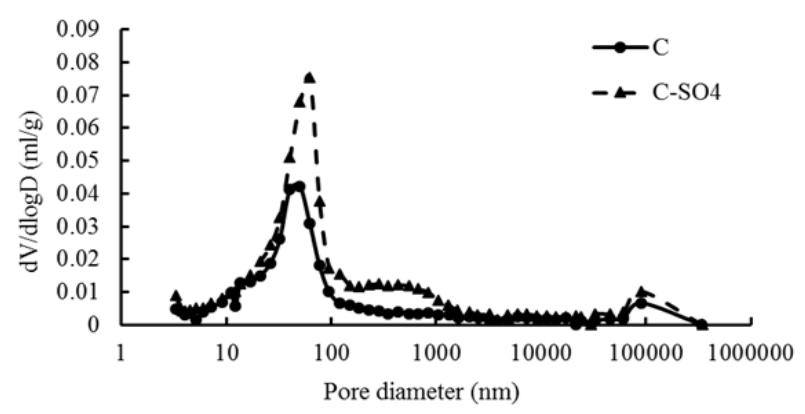

Fig.7. pore distribution of control group concrete under sulfuric acid solution

From Fig. 7, after erosion, the amount of pores whose diameter is among $100 \mathrm{~nm}-1000 \mathrm{~nm}$ increase. This dimension of pores can make the anti-permeability of concrete decrease. Therefore, the control group of concrete has a worse anti-acid corrode performance.

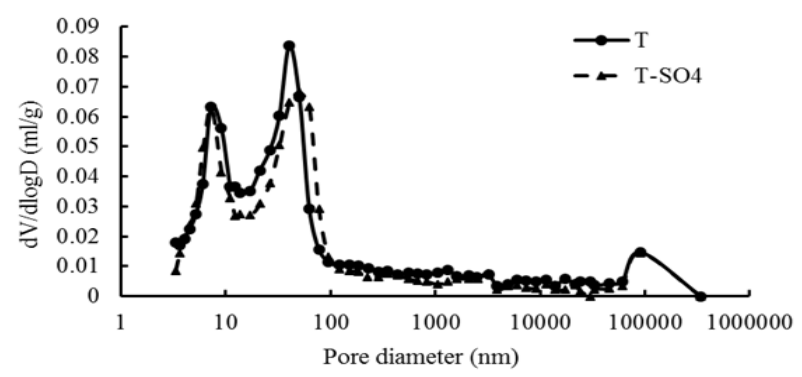

Fig.8. pore distribution of treatment group concrete under sulfuric acid solution
From Fig. 8, after eroded, the pore distribution still keeps as similar as before. Comparing Fig. 7 and Fig. 8, Treatment group behave better than the control group for the erosion of sulfuric acid and sodium sulfate mixture solution. The same situation also happens in the hydrochloric acid and sodium chloride mixture solution. Therefore, from pore distribution figure, it can be concluded that the concrete with additional materials has better anti-acid performance.

\section{Conclusions}

To enhance the performance of anti-acid erosion, silica fume, silicon nitride, organic silicone emulsion agent and fly ash ceramsite are all mixed into concrete as admixture. By compressive strength test and pore structure test, it can be concluded that the concrete with these admixtures has better anti-acid performance than common concrete without mixing these admixtures. Some conclusions can be shown as follow.

(1) The compressive strength increase along with the curing age increasing. The early age compressive strength of concrete with additional materials is lower than the common concrete. While, after $28 \mathrm{~d}$ curing, the compressive strength of concrete with additional materials is higher.

(2) No matter in sulphate or in hydrochloride, the compressive strength of concrete with additional materials is higher than the common concrete. The pore distribution curve can keep steady and the pores whose diameter is 100-1000nm don't not increase.

(3) Concrete with silica fume, silicon nitride, organic silicone emulsion agent and fly ash ceramsite has good anti-acid corrode performance.

\section{Acknowledgement}

This work was supported by the Basic Research Found for National Public Welfare Scientific Research Institutions [grant numbers 2017-9004].

\section{References}

1. F.Yuan Dong, S.Suo Zheng, M.Chen Song. Materials Review A: Summarize Section.,32,8 (2018) (In Chinese)

2. L.Yu. Micro-Properties of Cement Concrete. (China Building Industry Press, 2017) (In Chinese)

3. J-Guo Sun, Y.Ling GU. Concrete. 10,4(2013) (In Chinese)

4. Y. Yang, H.Ying ZHU, X.Min WANG, L.Huan LU, X.Li XIE. Concrete. 9,4(2017) (In Chinese)

5. S. Han, M.Zhe An, R. Guo, G. Liu. Journal of Building Materials. 18,6(2015) (In Chinese)

6. L. Yu. Study on durability of cement concrete in multi erosion. (Doctor Degree of Beijing University of Technology, 2013) (In Chinese) 